\section{REPAIR OF LONG-SEGMENT TRACHEAL STENOSIS IN INFANCY}

Long-segment stenosis of the trachea in infancy is a considerable surgical challenge because the infants are generally extremely ill and the airway is small. The optimal type of repair is not clearly defined. This report summarizes our experience with rib cartilage tracheoplasty done with cardiopulmonary bypass. Six patients underwent repair of long-segment tracheal stenosis between September 1987 and September 1994. The mean age was 14 weeks (range 1 to 58 weeks). Patients had stenosis of at least $70 \%$ of the tracheal length, typically with complete cartilaginous rings. In all patients stenosis was repaired by placement of a section of rib cartilage as an augmentation patch into the anterior surface of the trachea, which had been incised through the entire length of the stenosis. To avoid distal airway intubation, we used cardiopulmonary bypass for all procedures, with a mean bypass duration of 110 minutes (range 54 to 175 minutes). Mechanical ventilation was required for a median of 11 days after the operation (range 7 to 81 days), and the median postoperative hospital stay was 17 days (range 12 to 180 days). All patients are long-term survivors. Complications included the need for extracorporeal membrane oxygenation to treat ventricular dysfunction in one patient and graft dehiscence requiring revision of the distal graft in another. The latter patient has required several treatments with a bronchoscope for removal of granulation tissue. All other patients are free of symptoms and have normal growth with a mean follow-up of 4.7 years (range 5 months to 7.6 years). We conclude that rib cartilage tracheoplasty for long-segment tracheal stenosis provides excellent results in short and intermediate follow-up. In addition, the use of cardiopulmonary bypass allows an unobstructed view of the tiny infant airway and thus permits a precise repair. (J THORAC CardiovasC SURG 1995;110:1504-12)

Robert D. B. Jaquiss, MD ${ }^{\mathrm{a}}$ (by invitation), Rodney P. Lusk, MD ${ }^{\mathrm{b}}$ (by invitation), Thomas L. Spray, MD, ${ }^{\mathrm{c}}$ and Charles B. Huddleston, $\mathrm{MD}^{\mathrm{a}}$ (by invitation), St. Louis, Mo., and Philadelphia, Pa. ong-segment tracheal stenosis in infancy is a rare _entity that has historically been associated with a poor outcome. ${ }^{1-4}$ The lack of an established therapy

From the Division of Cardiothoracic Surgery, Department of Surgery, ${ }^{a}$ and the Department of Otolaryngology, ${ }^{b}$ Washington University School of Medicine, St. Louis, Mo., and the Division of Cardiothoracic Surgery, Department of Surgery, University of Pennsylvania School of Medicine, Philadelphia, Pa.

Read at the Seventy-fifth Annual Meeting of The American Association for Thoracic Surgery, Boston, Mass., April 23-26, 1995.

Address for reprints: Charles B. Huddleston, MD, 5W24, St. Louis Children's Hospital, 1 Children's Place, St. Louis, MO 63110.

Copyright (C) 1995 by Mosby-Year Book, Inc.

$0022-5223 / 95 \$ 5.00+0 \quad \mathbf{1 2 / 6 / 6 7 8 0 5}$ for this disorder is attested to by the wide variety of therapeutic approaches that have been reported, including conservative observation, ${ }^{4}$ balloon dilatation tracheoplasty, ${ }^{5}$ resection, ${ }^{5-11}$ or augmentation tracheoplasty. ${ }^{11-30}$ It was not until the early $1980 \mathrm{~s}$ that reports of survival first appeared. ${ }^{14,17}$ In the setting of shorter segments of tracheal stenosis, that is, less than $50 \%$ of the tracheal length, success has been reported with segmental resection. ${ }^{6-11}$ For stenosis involving more that $50 \%$ of the tracheal length, resection has not been thought to be possible. ${ }^{11,31,32}$ Alternatives that have been applied to long-segment stenosis in children include balloon dilatation, ${ }^{5}$ slide tracheoplasty, ${ }^{31,32}$ and augmentation tracheoplasty. ${ }^{11-30}$ The most successful of these approaches has been pericardial patch augmentation. ${ }^{24-27}$ 
Table I. Results

\begin{tabular}{|c|c|c|c|c|c|}
\hline $\begin{array}{c}\text { Patient } \\
\text { No. }\end{array}$ & $\begin{array}{l}\text { Age } \\
(w k)\end{array}$ & $\begin{array}{l}C P B \\
\text { Time } \\
\text { (min) }\end{array}$ & $\begin{array}{l}\text { Postop. } \\
\text { days on } \\
\text { ventilator }\end{array}$ & $\begin{array}{l}\text { Postop. } \\
\text { days to } \\
\text { discharge }\end{array}$ & $\begin{array}{c}\text { Postop. } \\
\text { bronchoscopies }\end{array}$ \\
\hline 1 & 58 & 133 & 13 & 17 & 3 \\
\hline 2 & 5 & 121 & 9 & 17 & 1 \\
\hline 3 & 8 & 54 & 10 & 14 & 2 \\
\hline 4 & 6 & 86 & 7 & 12 & 1 \\
\hline 5 & 4 & 175 & 81 & 180 & 22 \\
\hline 6 & 1 & 91 & 12 & 24 & 3 \\
\hline Mean & & 110.0 & 22.0 & 44.0 & \\
\hline $\begin{array}{l}\text { Standard } \\
\text { Deviation }\end{array}$ & & 42.3 & & & \\
\hline
\end{tabular}

$C P B$, Cardiopulmonary bypass; $S D$, standard deviation.

A variety of technical options have been described for reconstruction of the trachea. The approach to the trachea may be by cervical incision, ${ }^{31,32}$ thoracotomy, ${ }^{21}$ or sternotomy. ${ }^{16,24-27}$ Physiologic gas exchange during tracheal reconstruction has been maintained by distal ventilation with a tube that crosses the operative field ${ }^{11,21,31,32}$ or by cardiopulmonary bypass. ${ }^{16,19,20,24-27}$ Numerous materials have been used or proposed as augmentation patches for the tracheoplasty, including the esophagus, ${ }^{22,23}$ pericardium, ${ }^{24-27}$ solvent-preserved dura, ${ }^{21}$ periosteum, ${ }^{30}$ and cartilage from either chondral ${ }^{13-21}$ or auricular sources. This article describes our preferred technique for the management of long-segment tracheal stenosis in the infant and reviews our experience with six children undergoing rib cartilage tracheoplasty performed with the aid of cardiopulmonary bypass.

\section{Methods}

Patients. During the period from September 1987 to September 1994, six infants whose ages ranged from 1 to 58 weeks (mean age 14 weeks) with the diagnosis of long-segment tracheal stenosis were treated at St. Louis Children's Hospital. Specific patient data are shown in Table I. (Three of these patients were included in an earlier report. ${ }^{16}$ ) The diagnosis was suspected because of unexplained respiratory distress, stridor, and difficulty with endotracheal intubation for other surgical procedures. The diagnosis was confirmed by examination with a rigid bronchoscope in all cases. In one child (patient 4) airway films suggested tracheal stenosis. Computed tomography, magnetic resonance imaging, and bronchography were not used.

Several of the children had required mechanical ventilation before definitive operative correction of the tracheal stenosis, either for respiratory distress in the newborn period or for general anesthesia for other operations. Associated diagnoses included tetralogy of Fallot in one child and the combination of patent ductus arteriosus and imperforate anus in another. Two children

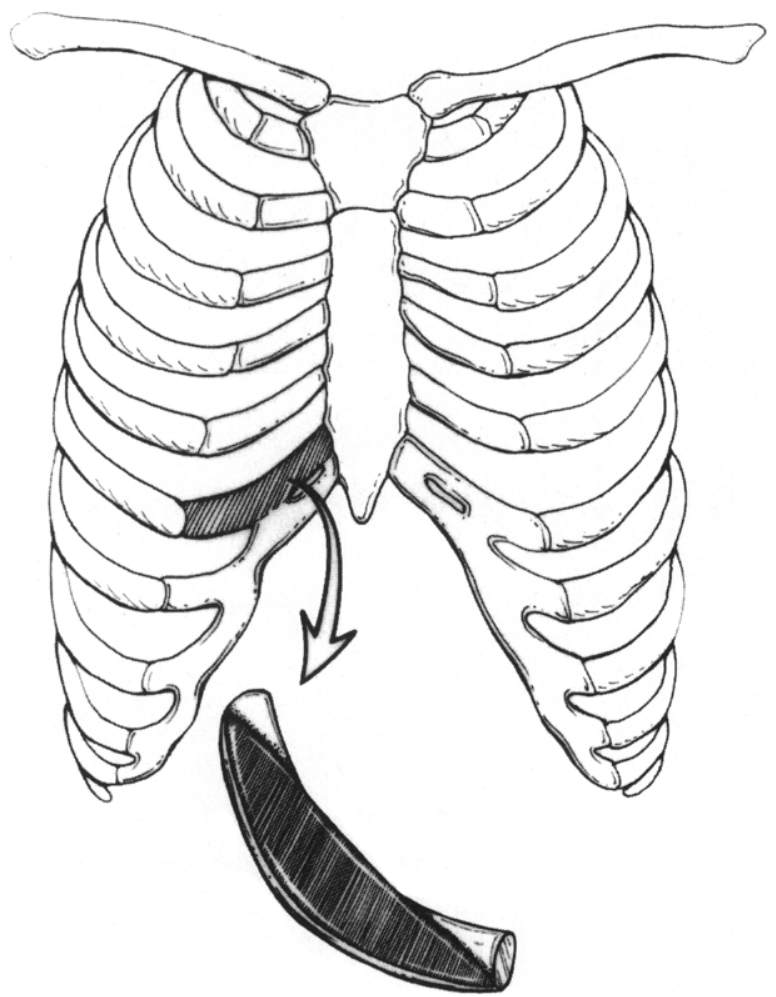

Fig. 1. Before sternal splitting, a segment of cartilage is harvested from the sixth or seventh rib. The cartilage is then tailored to correspond to the subsequent tracheotomy.

had significant respiratory distress necessitating intubation in the neonatal period, and one of these required extracorporeal membrane oxygenation (ECMO). No other bronchopulmonary abnormalities were identified; specifically, no patient had a tracheal origin of the right upper lobe bronchus or pulmonary agenesis. No vascular anomalies (rings or pulmonary artery slings) were detected, either before or during the operation, and no patient had a coexistent tracheoesophageal fistula. Complete cartilaginous rings were present in five of the six patients.

Surgical technique. All operations were performed in the following sequence: After the induction of general anesthesia, initial examination with a rigid bronchoscope was performed to identify the degree of stenosis and its proximal extent. Endotracheal intubation or ventilation by means of the bronchoscope was then accomplished. The cartilage graft was harvested via the sternotomy incision (Fig. 1). Median sternotomy was performed while preliminary preparation of the cartilage graft was being done. The trachea was then dissected and exposed on its anterior surface. Patients were given heparin and were cannulated for cardiopulmonary bypass via the right atrium and ascending aorta. After the start of bypass the endotracheal tube was removed and the bronchoscope was reinserted. A 25-gauge needle was then inserted in the midline of the 


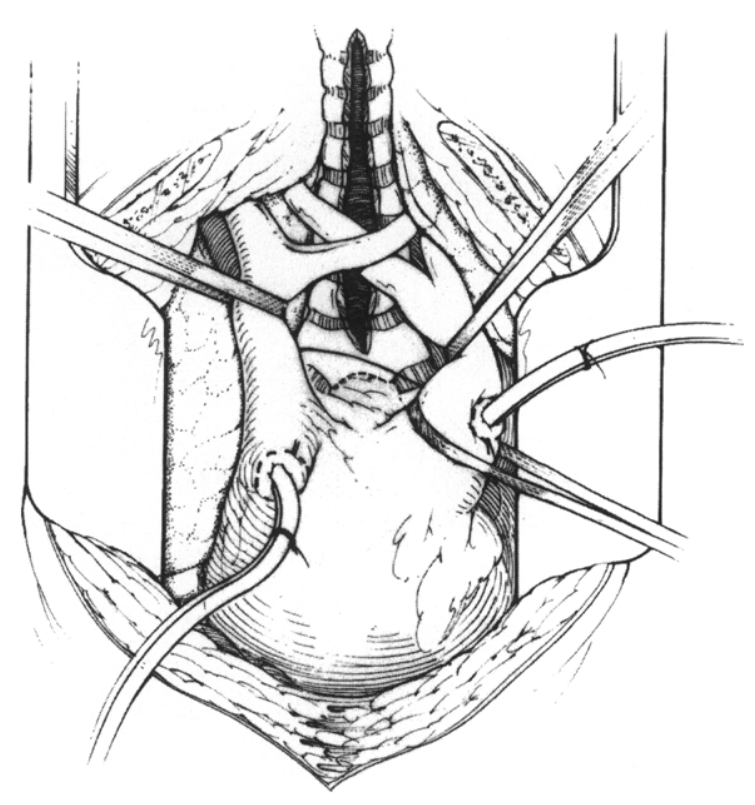

Fig. 2. Exposure of the trachea through a sternotomy is demonstrated, including the relative positions of bypass cannulas and retraction of the great vessels for optimum exposure. The distal end of the tracheotomy is typically extended all the way to the carina.

anterior wall at the proximal end of the stenosis, guided by bronchoscopic visualization. A scalpel was used to open the anterior wall of the stenotic segment down through the distal end of the stenosis as identified by the bronchoscopic examination (Fig. 2). This incision occasionally extended onto the main-stem bronchi. It was notable that the external appearance of the trachea often underestimated the proximal or distal extent of the stenosis, which emphasizes the importance of a coordinated approach to the tracheal incision with bronchoscopic guidance. When the extent of stenosis was clear, the segment of chondral cartilage was tailored to a shape and size suitable for the tracheotomy. Care was taken to preserve the perichondrium.

The cartilage graft was then interposed in the tracheotomy and secured with interrupted stitches of nonabsorbable monofilament suture (Fig. 3). The graft was placed with the perichondrial surface toward the lumen of the trachea. Care was taken to avoid exposure of any suture material to the lumen of the airway in an attempt to minimize the subsequent formation of granulation tissue. After completion of the graft suture line, the anesthesiologist insufflated air and the suture line was confirmed to be airtight with additional sutures placed as necessary. The endotracheal tube was removed and a rigid bronchoscope was again used to confirm the adequacy of the reconstruction and clear any retained secretions. The tube was replaced under bronchoscopic guidance with the distal end of the endotracheal tube positioned proximal to the distal end of the cartilage graft (Fig. 3). Mechanical ventilation was then commenced and the patient was weaned from bypass. After heparin reversal, the sternotomy was closed over a mediastinal drain in a standard fashion.

Postoperative care. Details of postoperative care included the maintenance of heavy sedation with the addition of muscle relaxants if necessary to minimize the motion of the endotracheal tube in the airway. Approximately 7 to 10 days after the operation the patient was returned to the operating room for examination with a rigid bronchoscope after removal of the endotracheal tube. If necessary, granulation tissue was removed. If the airway was believed to be stable and adequately healed, the patient was extubated. If the granulation tissue was believed to be excessive or if healing was judged inadequate, the endotracheal tube was replaced and the patient was returned to the intensive care unit. This process was repeated until extubation was successful.

\section{Results}

All patients are long-term survivors with follow-up ranging from 6 months to 7.6 years (Table I). Mean bypass time was 110 minutes, with a range of less than 1 hour to slightly less than 3 hours. Granulation tissue developed in all but one patient. However, this was seldom a problem (except in one patient, whose case is discussed in more detail later). Once the patient was extubated, usually in less than 2 weeks, the subsequent hospital stay was brief, typically 4 to 7 days. Postoperative bronchoscopic treatment was needed three or fewer times in all but one patient. In late follow-up, all patients are growing well and are free of symptoms, with one notable exception. Flow volume loops obtained during follow-up examinations were within normal limits.

Case descriptions. Patient 1 was a 14-month-old boy who underwent repair of tetralogy of Fallot at 13 months of age. The postoperative course was notable for respiratory distress believed to be caused by tracheitis. After a course of antibiotics his symptoms lessened and he was sent home. At home the respiratory distress worsened and he was readmitted. Bronchoscopic examination confirmed the diagnosis of tracheal stenosis with complete tracheal rings. The stenosis extended from just below the cricoid to the carina and was repaired with two pieces of chondral cartilage. He was extubated on postoperative day 13 after removal of minimal granulation tissue from the distal suture line. Follow-up bronchoscopic study showed no recurrence of the granulation tissue. He remains free of symptoms at 7.6 years of follow-up.

Patient 2 was a 5-week-old boy who required a period of mechanical ventilation at birth for hyaline membrane disease. He was able to be weaned from 


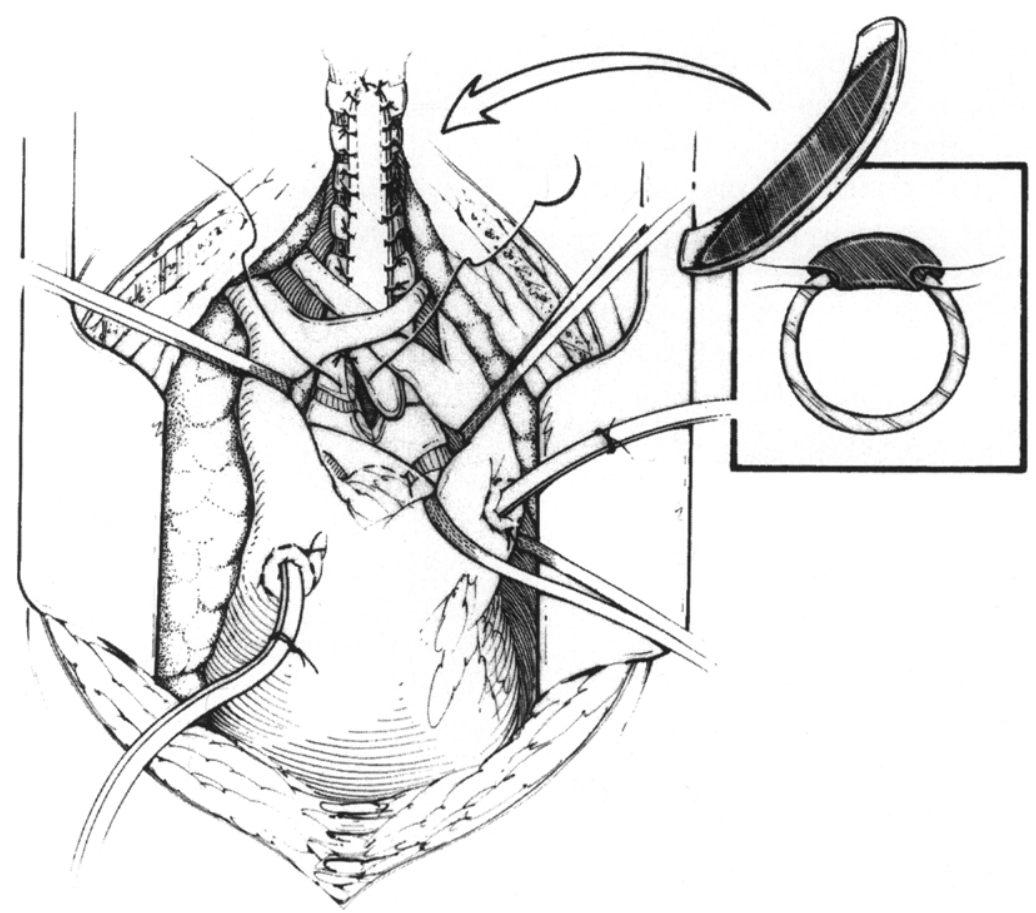

Fig. 3. Placement of the cartilage graft is indicated. The graft is oriented with preserved perichondrium placed on the lumenal side and secured with interrupted nonabsorbable monofilament suture. Intraluminal suture exposure is avoided and the graft is seated on the tracheotomy, rather than being allowed to prolapse into the lumen. The distal end of the endotracheal tube is indicated by a dotted line. Note that this is well above the carina and distal end of the graft.

the ventilator and was discharged to his home, but he had recurrent respiratory distress. He was readmitted to the hospital, and bronchoscopic examination revealed tracheal stenosis. At operation, the stenosis extended from just below the thoracic inlet all the way into both main-stem bronchi. The cartilage graft was tailored to extend out onto both bronchi. Postoperative bronchoscopic study showed no evidence of granulation tissue, and he was extubated on postoperative day 9 . He remains free of symptoms at 7.2 years of follow-up.

Patient 3 was a 2 -month-old girl who had progressive dyspnea and difficulty feeding at home. She was admitted for evaluation of failure to thrive. Chest roentgenograms revealed nonspecific infiltrates and marked stridor developed in the hospital. A bronchoscopic study showed tracheal stenosis with complete tracheal rings. At operation the stenosis was found to extend from the thoracic inlet to the carina. A postoperative bronchoscopic examination revealed minimal granulation tissue, which was removed. She was extubated uneventfully on postop- erative day 10 and remains free of symptoms at 5.9 years of follow-up.

Patient 4 was a 6-week-old boy who required ECMO support shortly after birth for persistent fetal circulation. He was weaned from ECMO and mechanical ventilation and eventually discharged to his home. After a brief stay at home he began having progressive respiratory distress. Airway films in the emergency room suggested tracheal stenosis, and bronchoscopic examination confirmed the diagnosis. He was not believed to have complete cartilaginous rings when the trachea was opened in the operating room. The stenosis was thought to be more compatible with scar formation resulting from excessive endotracheal tube trauma during the period of mechanical ventilation and ECMO. After tracheoplasty, a low cardiac output developed, necessitating high-dose vasopressors. Ultimately, he required ECMO, established via a transthoracic approach. Echocardiography showed severe biventricular dysfunction of unknown origin, which improved during the next 4 days. He was weaned from ECMO, and 
on postoperative day 7 he was able to be extubated. $\mathrm{He}$ required bronchoscopic removal of granulation tissue at the distal anastomosis one more time. At the time of discharge the findings from the echocardiogram had returned to normal, and he remains free of symptoms at 5.5 years of follow-up.

Patient 5 was a 4-week-old infant with progressive respiratory distress in whom stridor was detected on inpatient evaluation of failure to thrive. Examination with a bronchoscope confirmed the presence of tracheal stenosis beginning $2 \mathrm{~cm}$ below the cricoid. With the trachea opened, complete tracheal rings were observed with an area of significant tracheomalacia at the carina and proximal main-stem bronchi. The distal malacic segment of the trachea collapsed on endoscopic evaluation after initial placement of a simple cartilage graft. The tracheotomy was therefore closed distally with pericardium, which was externally stented with a segment of chondral cartilage. The proximal airway was reconstructed with a simple cartilage graft. On bronchoscopic evaluation at postoperative day 10 , however, the distal airway was found to collapse with partial dehiscence of the pericardial patch. The patient was returned to the operating room for revision of the distal graft with auricular cartilage, which extended the graft out onto both bronchi. (Auricular cartilage was used because of the need for a fairly small, thin patch for the revision and because of previous good experience with this material in laryngotracheal reconstruction.) The patient then began to have recurrent formation of granulation tissue. A tracheostomy tube was inserted when it became apparent that repetitive bronchoscopic removal of granulation tissue would be necessary. He was eventually weaned from mechanical ventilation after 22 bronchoscopic procedures on the postoperative day 81 . He was discharged to his home with the tracheostomy tube still in place but has required several subsequent endoscopic debridements of the airway. The intervals between procedures has been increasing, and 1.6 years have now elapsed since the tracheoplasty.

Patient 6 was a 1-week-old boy noted to have difficulty with ventilation while intubated after a laparotomy for an imperforate anus. A bronchoscopic examination confirmed the presence of tracheal stenosis with complete tracheal rings. Additional observations were a patent ductus arteriosus and a persistent left superior vena cava. He underwent augmentation tracheoplasty via median sternotomy with cardiopulmonary bypass, at which time the ductus arteriosus was also ligated. In the postoperative period he required one change of the endotracheal tube when it became clogged with dried secretions. Subsequently he was extubated on postoperative day 12 and remains free of symptoms 6 months after the operation.

\section{Discussion}

In the past 15 years the management of longsegment tracheal stenosis in infancy has evolved and improved significantly, as a variety of surgical approaches and numerous sources of tissue for tracheal augmentation have been used. This formerly hopeless disorder can now be approached with some degree of optimism, with reported survival of $70 \%$ to $90 \%$ in recent series. ${ }^{21,24,25}$ Nonetheless, even these series are less than ideal both in terms of operative survival and because of the frequent need for repeated interventions to remove granulation tissue and the necessity for tracheostomies for longterm stenting. ${ }^{24}$ The present series compares favorably with historical results with $100 \%$ survival, fewer postoperative interventions, and less morbidity. The two most attractive alternative strategies are pericardial tracheoplasty and slide tracheoplasty.

The most commonly reported alternative to rib cartilage augmentation has been the use of autologous pericardium. ${ }^{24-27}$ The technique was originally described by Idriss and associates ${ }^{27}$ and involves sternotomy, cardiopulmonary bypass for gas exchange, and suspension of the pericardial patch with sutures to prevent patch prolapse into the lumen. This experience was updated in $1994^{25}$ and now includes 18 patients with 15 hospital survivors $(83 \%)$. The three deaths were attributable to mediastinitis, graft disruption, and recurrent stenosis. Six of the 15 survivors required tracheostomy (40\%), two for distal stenting and four for management of secretions with carinal stenosis. Postoperative bronchoscopic treatment was common in the survivors, with the mean number of procedures per patient being 16 for those with stenosis extending to the carina and 16.8 for those with stenosis extending into the bronchi. A smaller series was reported in 1991 by Heimansohn and associates ${ }^{24}$ using the same technique. Eight of their seven patients were operative survivors $(88 \%)$, with two of seven $(29 \%)$ requiring either tracheostomy or prolonged mechanical ventilation.

Advantages of pericardium as a patch material include its pliability and ease of handling, which contribute to a tight seal with an airtight suture line. 
The material is also readily available and plentiful. Except for pliability, all of these attributes also describe costal cartilage as used in this series. A notable disadvantage of pericardium as a tracheal graft is its collapsibility. Idriss, ${ }^{27}$ Heimansohn, ${ }^{24}$ and their colleagues reported the suspension of the graft to anterior mediastinal structures with suture material to create a sort of external stent. The endotracheal tube then provides an internal stent. In contrast, cartilage grafts are more rigid, and in this series the endotracheal tube was purposely not advanced to the distal end of the graft. This was possible because of the "auto-stenting" feature of cartilage and may explain the low incidence of permanent tracheostomies required in our series $(1 / 6,15 \%)$. We believe the more proximal positioning of the tube allowed by a cartilage graft provides for significantly less endotracheal trauma in the carinal region and thus may explain the low incidence of troublesome granulation tissue seen in our series in contrast to experience with pericardial grafts. ${ }^{25}$ With the exception of one patient, all of our patients required three or fewer postoperative bronchoscopic treatments in contrast to the mean of 16 or 17 reported with the pericardial grafts. ${ }^{25}$ Thus the cartilage appears to require much less postoperative "maintenance" and, in general, to be a more trouble-free graft.

A novel technique for the management of longsegment tracheal stenosis is slide tracheoplasty, proposed by Tsang and colleagues ${ }^{32}$ and used by Grillo. ${ }^{31}$ In this technique, which is accomplished by cervical incision or thoracotomy, the trachea is divided transversely through the middle of the stenosis. Distal ventilation is used for gas exchange. The two ends are spatulated by a longitudinal slit on the anterior surface of one end and posterior surface of the other end. (Tsang and coworkers applied the posterior longitudinal split to the distal segment and Grillo to the proximal segment.) The spatulated ends are then advanced over each other and anastomosed together in an extended end-to-end fashion. Stents are not used. In the original description ${ }^{32}$ the case histories of two infants were reported, one aged 3 months and one aged 10 months. The older child died of pneumonia after the operation. The younger infant survived with normal flow volume loops in follow-up. In Grillo's report, ${ }^{31}$ two small children, aged 3 months and 3 years, were included with good functional outcome. Two young adults were also described in Grillo's report with good symptomatic outcomes and significant improvement in results of pulmonary function testing. Whether their stenoses were as severe as is seen in infants is not certain.

Purported or potential advantages of slide tracheoplasty in comparison with either cartilage or pericardial augmentation include the avoidance of graft material, avoidance of stenting, and avoidance of the formation of granulation tissue. Although all of these are desirable, the actual advantages of slide tracheoplasty await wider application to larger series of young patients, because the combined reported experience in children under age 5 years includes only four patients. ${ }^{31,32}$ The growth potential of the long suture line may be as good as has been seen with augmentation but remains speculative. Grillo ${ }^{31}$ has suggested that the most important advantage of slide tracheoplasty may be the avoidance of nonepithelial tissue in the airway, which he believes to be the explanation for the excessive granulation tissue seen with pericardial grafts. DeLorimier and colleagues ${ }^{11}$ have suggested that granulation is likely with cartilage grafts involving $30 \%$ or more of the luminal circumference. In this series granulation tissue was not a problem for five of the six patients $(83 \%)$. In the one child who did require multiple debridements of granulation tissue, we believe this was a result of the unfortunate combination of distal malacia and proximal stenosis, use of pericardium as a component of the distal augmentation graft, and the excessive operative manipulation required during the reoperation. Rapid epithelialization of cartilage grafts in the airway has been demonstrated in our laboratory in a rabbit model, with complete epithelialization of auricular cartilage in 7 days and rib cartilage in 14 days. ${ }^{34}$ Thus the avoidance of mesenchyme in the airway may be less important than has been suggested by Grillo. ${ }^{31}$ Other features of slide tracheoplasty, such as early extubation, are attractive if they can be confirmed in larger series of patients. We do have some hesitation about the technique in more extensive stenoses involving the bronchi. Grillo ${ }^{31}$ suggested that additional operative procedures may be required in the patient from his series who had bronchial stenosis, and this need for additional operations may confine the application of slide tracheoplasty to simpler tracheal stenoses.

A continuing area of discussion in tracheal surgery in children has been the use of cardiopulmonary bypass. We and others ${ }^{16,19,20,24-27}$ have found it extremely useful in uncluttering the operative field and simplifying the operation. Others have preferred to avoid bypass. ${ }^{11,21,31,32}$ The choice proba- 
bly reflects the bias of the surgeon in that surgeons with cardiac orientation seem to prefer bypass and surgeons with general thoracic orientation seem to avoid it. In the current series, bypass times were all within an acceptable and safe range. No series, including the current one, has included a complication referable to its use, although one of our patients had unexplained and reversible ventricular dysfunction that may have been caused by bypass in some fashion. We would suggest that cardiopulmonary bypass be available as a backup, particularly in the smallest infants, even if it is not used routinely.

On the basis of the current series, we believe anterior costal cartilage tracheoplasty represents an attractive therapeutic option for infants with longsegment tracheal stenosis, versatile enough to be applied to the most complex and extensive stenoses. In comparison with currently available alternative methods of treatment, it provides excellent functional results with a low rate of postoperative problems. Thus we consider it the treatment of choice for long-segment tracheal stenosis in infancy.

\section{REFERENCES}

1. Campbell DN, Lilly JR. Surgery for total congenital tracheal stenosis, J Pediatr Surg 1986;21:934-5.

2. Janik JS, Nagaraj HS, Yacoub U, Groff DB. Congenital funnel-shaped tracheal stenosis: an asymptomatic lethal anomaly of early infancy. J THORAC CARdIOVASC SURG 1982;83:761-6.

3. Hoffer ME, Tom LWC, Wetmore RF, Handler SD, Potsic WP. Congenital tracheal stenosis: the otolaryngologist's perspective. Arch Otolaryngol Head Neck Surg 1994;120:449-53.

4. Benjamin B, Pitkin J, Cohen D. Congenital tracheal stenosis. Ann Otol 1981;90:364-71.

5. Bagwell CE, Talbert JL, Tepas JJ III. Balloon dilatation of long-segment tracheal stenosis. J Pediatr Surg 1991;26:153-9.

6. Healy GB, Schuster SR, Jonas RA, McGill TJI. Correction of segmental tracheal stenosis in children. Ann Otol Rhinol Laryngol 1988;97:444-7.

7. Nakayama DK, Harrison MR, de Lorimier AA, Brasch RC, Fishman NH. Reconstructive surgery for obstructing lesions of the intrathoracic trachea in infants and small children. J Pediatr Surg 1982;17:85468.

8. Harrison MR, Heldt GP, Brasch RC, de Lorimier AA, Gregory GA. Resection of distal tracheal stenosis in a baby with agenesis of the lung. J Pediatr Surg 1980;15:938-43.

9. Salzer GM, Hartl H, Wurnig P. Treatment of tracheal stenoses by resection in infancy and early childhood. Prog Pediatr Surg 1987;21:72-5.
10. Halsband $\mathbf{H}$. Long-distance resection of the trachea with primary anastomosis in small children. Prog Pediatr Surg 1987;21:76-85.

11. DeLorimier AA, Harrison MR, Hardy K, Howell LJ, Adzick NS. Tracheobronchial obstructions in infants and children: experience with 45 cases. Ann Surg 1990;212:277-89.

12. Loeff DS, Filler RM, Vinograd I, Ein SH, et al. Congenital tracheal stenosis: a review of 22 patients from 1965 to 1987. J Pediatr Surg 1988;23:744-8.

13. Mambrino LJ, Kenna MA, Seashore J. Surgical management of tracheal stenosis in an infant with multiple congenital anomalies: When is baby inoperable? Ann Otol Rhinol Larngol 1991;100:198-200.

14. Kimura K, Mukohara N, Tsugawa C, et al. Tracheoplasty for congenital stenosis of entire trachea. J Pediatr Surg 1982;17:869-71.

15. Tsugawa C, Kimura K, Muraji T, Nishijima E, Matsumoto $\mathrm{Y}$, Murata $\mathrm{H}$. Congenital stenosis involving a long segment of the trachea: further experience in reconstructive surgery. J Pediatr Surg 1988;23:471-5.

16. Van Meter CH Jr, Lusk RM, Muntz H, Spray TL. Tracheoplasty for congenital long-segment intrathoracic tracheal stenosis. Am Surg 1991;57:157-60.

17. Saad S, Falla A. Management of intractable and extensive tracheal stenosis by implantation of cartilage graft. J Pediatr Surg 1983;18:472-4.

18. Weber TR, Connors RH, Tracy TF Jr. Congenital tracheal stenosis with unilateral pulmonary agenesis. Ann Surg 1991;213:70-4.

19. Yamaguchi M, Oshima Y, Hosokawa Y, et al. Concomitant repair of congenital tracheal stenosis and complex cardiac anomaly in small children. J THORAC Cardiovasc Surg 1990;100:181-7.

20. Jonas R. Invited letter concerning: tracheal operations in infancy. J Thorac Cardiovasc Surg 1990; 100:316-7.

21. Lobe TE, Hayden CK, Nicolas D, Richardson CJ. Successful management of congenital tracheal stenosis in infancy. J Pediatr Surg 1987;12:1137-42.

22. Ein SH, Friedberg J, Williams WG, Rearon B, Barker GA, Mancer K. Tracheoplasty: a new operation for complete congenital tracheal stenosis. J Pediatr Surg 1982;17:872-8.

23. Sasaki S, Hara F, Ohwa T, Eguchi T, Masaoka A. Esophageal tracheoplasty for congenital tracheal stenosis. J Pediatr Surg 1992;27:645-9.

24. Heimansohn DA, Kesler KA, Turrentine MW, et al. Anterior pericardial tracheoplasty for congenital tracheal stenosis. J Thorac Cardiovasc Surg 1991;102: 710-6.

25. Dunham ME, Holinger LD, Backer CL, Mavroudis C. Management of severe congenital tracheal stenosis. Ann Otol Rhinol Laryngol 1994;103:351-6.

26. Cosentino CM, Backer CL, Idriss FK, Holinger LD, Gerson CR, Mavroudis C. Pericardial patch tracheo- 
plasty for severe tracheal stenosis in children: intermediate results. J Pediatr Surg 1991;26:879-85.

27. Idriss FS, DeLeon SY, Ilbawi MN, Gerson CR, Tucker GF, Holinger L. Tracheoplasty with pericardial patch for extensive tracheal stenosis in infants and children. J Thorac Cardiovasc Surg 1984;88: 527-36.

28. Gustafson RA, Hrabovsky EE. Intercostal muscle and myo-osseous flaps in difficult pediatric thoracic problems. J Pediatr Surg 1982;17:541-5.

29. Willner A, Velez FJ. Rib-muscle pedicle flap for the repair of congenital tracheal stenosis. Ann Otol Rhinol Laryngol 1994;103:601-8.

30. Cohen RC, Filler RM, Konuma K, Bahoric A, Kent $\mathrm{G}$, Smith $\mathrm{C}$. The successful reconstruction of thoracic tracheal defects with free periosteal grafts. $\mathrm{J}$ Pediatr Surg 1985;20:852-8.

31. Grillo HC. Slide tracheoplasty for long-segment congenital tracheal stenosis. Ann Thorac Surg 1994;58: 613-21.

32. Tsang V, Murday A, Gillbe C, Goldstraw P. Slide tracheoplasty for congenital funnel-shaped tracheal stenosis. Ann Thorac Surg 1989;48:632-5.

33. Louhimo I, Leijala M. Cardiopulmonary bypass in tracheal surgery in infants and small children. Prog Pediatr Surg 1987;21:58-63.

34. Heatly DG, Garner FT, Clary RA, Lusk RP. Auricular cartilage versus costal cartilage as a grafting material in experimental laryngotracheal reconstruction. Laryngoscope [In press].

\section{Discussion}

Dr. Douglas J. Mathisen (Boston, Mass.). Anybody who works in this area appreciates the difficulties of dealing with these airway problems in these very tiny infants.

There is no single accepted treatment for this problem. Because of that, persons who work in this area must be aware of all of the possibilities that exist to treat this problem so that they can tailor their solution to the individual problem according to the patient's needs and the surgeon's own technical abilities. For this reason, we are indebted to the authors for reintroducing this technique and also for sharing with us their excellent results.

The same thought holds true for the use of cardiopulmonary bypass. Certainly, cardiac surgeons are more familiar with this type of technique for maintaining oxygenation and general thoracic surgeons are more familiar with using cross-incisional ventilation of the distal airway. There may be times when either technique is not suitable. Therefore we must be aware that cardiopulmonary bypass can be used safely.

You have discussed the technical details of preparing the rib graft and tailoring the ends. Do you make any effort to tailor the graft in terms of its thickness?

Second, do you make any attempt to cover the graft or separate it from the overlying innominate artery? Obviously a leak or a problem with the overlying artery may lead to catastrophic problems. Do you make any attempt to cover it with any kind of pedicled viable tissue?
One of the purported advantages of this technique is that it provides a more stable airway. I wonder whether it is absolutely necessary to leave these patients intubated for the length of time that you have used in this series. Certainly it is an improvement over the duration of intubation that has been required in other series in which other materials have been used, but I wonder whether even this could be shortened. Regardless of where the tube is positioned, the longer it is in place, the more likely it is to affect the end result and contribute to granulations.

You showed us a beautiful demonstration of a postoperative bronchoscopic study in one patient. Have you done biopsies to see if this is truly reepithelialized? This has always been one of the problems in dealing with the various substitutes. Is anything known about the fate of the cartilage graft? Have you done any radiologic studies or do you have any sense as to whether this free graft has been preserved over time or is it simply incorporated into the surrounding tissues?

Finally, do you think that this technique has any applicability in shorter airway stenoses because of the excellent results you have achieved?

Dr. Jaquiss. To answer your questions in sequence, we do nothing to thin the cartilage. It might have been helpful in the particular infant that I mentioned, but we do not do anything to split it. Technically speaking, we do not do anything to cover the graft, although other authors have done that, particularly with pericardial grafts, interposing thymus or mediastinal tissue to protect the graft.

We have some early bronchoscopic results regarding the cartilage graft, but we have not done biopsies to confirm the presence or absence of respiratory mucosa. We do have some experimental data that suggest that cartilage grafts in the airway become epithelialized by 2 to 3 weeks with normal respiratory epithelium.

We do not have long-term bronchoscopic data to indicate that the cartilage has grown or that the remainder of the airway has been allowed to grow by getting the children through this first particularly rocky period. That would be speculation on my part.

For treating a short-segment stenoses, the tried-andtrue approach is resection with primary end-to-end anastomosis. If the segment were short enough to allow that, I would use that approach.

I think we are more conservative than we need to be regarding duration of ventilatory support. When pericardium has been used, because of the floppiness of that material in the airway, it is reasonable to wait at least 10 days to 2 weeks before attempting extubation so that the worry about the material prolapsing into the lumen is not present. I do not think that is necessary with cartilage, but we have not had the courage to undertake that experiment yet and have chosen to do what has worked for us. I certainly think that is an area of improvement that we could investigate.

Dr. Gerhard Ziemer (Tuebingen, Germany). I would like to stress the last sentence of Dr. Jaquiss's abstract, namely, that the use of cardiopulmonary bypass does allow an unobstructed view of the tiny infant airway and does permit a precise repair.

Formerly in Hannover and now in Tuebingen, I have experience with long-segment tracheal resection with car- 
diopulmonary bypass in six infants, three of whom had extensive stenotic hypoplastic tracheal disease in the magnitude reported by Dr. Jaquiss. Besides using a major part of the slide procedures in a fashion similar to that just reported, we differ by doing extensive tracheobronchial dissection and perform resection and end-to-end anastomosis.

In the first of these very long tracheal stenoses, we actually had to leave one ring cartilage in place, and the patient, now at the age of 4 years, will be reoperated on for a second resection. We then, despite certain concerns, added laryngeal release in two other infants. This laryngeal release was performed by an ear, nose, and throat colleague using microsurgical techniques that included an additional oblique anterior neck incision before sternotomy. This technique, widely known from operations in adults, clearly facilitated very long tracheal segment resection in these infants without tension at the anastomosis.

Dr. Jaquiss, despite your excellent results with this rather complicated technique, do you also still see some indications for mere resection in long-segment tracheal stenosis in infancy?

Dr. Jaquiss. The limits of resection have been tested by Dr. Grillo and his colleagues at Massachusetts General Hospital in adults, and to some extent they have been tried in infants by other groups. In San Francisco attempts have been made at tackling very long-segment stenoses, up to $70 \%$ of the tracheal length. The results in that subset of patients, which is a small portion of a very small group of patients, have not been encouraging. I would be hesitant to apply simple resection and end-to-end anastomosis, even with adjunctive release maneuvers such as hilar or laryngeal release. If the segment of trachea involved is more than $50 \%$, I would be hesitant to apply resection.

Dr. Carl L. Backer (Chicago, Ill.). Since 1982, 24 children with long-segment tracheal stenosis, all with complete tracheal rings, have been operated on at Children's Memorial Hospital in Chicago. Our technique was first reported by the late Dr. Farouk Idriss at this meeting in New York City in 1984. Our approach has been similar to yours in many respects. All patients in our series were operated on with the use of cardiopulmonary bypass. Dr. Idriss also emphasized the suture placement outside of the tracheal lumen. However, in our patients, all of the tracheas were patched with autologous pericardium instead of the rib cartilage graft used in your patients.

In our series there were two early deaths in the 24 patients for an operative survival of $92 \%$. The first death occurred in an 8-day-old child who had associated agenesis of the right lung. The second death occurred in the only patient in our series with a significant patch dehiscence, who died of mediastinitis after two reoperations. We have had three late deaths, all from airway complications, at 5, 7 and 13 months after the operation. I would speculate that one of the advantages of the rib tracheoplasty may be the avoidance of patch tracheomalacia and contraction, which was a problem in the patients who died late.

I have one observation and three questions. In our series of 24 patients there were eight who had associated pulmonary artery sling, or fully one third of the patients. It is striking that none of your patients had this associated anomaly, and I am curious as to how this was ruled out in these patients.

My questions really focus on your choice of rib cartilage instead of pericardium. First, is the rib cartilage ever too short? In our series many of the tracheas were stenotic from the cricoid all the way to the carina, which can be about a 4 to $5 \mathrm{~cm}$ length, even in infants. One of the advantages of the pericardium is that it is always possible to harvest a long enough piece. In a similar vein, often the trachea is so narrow that when you finish the tracheoplasty the tracheal lumen is at least $50 \%$ pericardium. Have you had circumstances in which the rib cartilage is not wide enough?

Do you think there is an increased risk of patch dehiscence when rib cartilage graft is used instead of pericardium? The pericardium seals very nicely and is not subject to the torque exerted by a rib, which is naturally curved.

Dr. Jaquiss. I cannot comment on the absence of pulmonary artery slings or other vascular anomalies; we just did not see them. These children had all had echocardiography by the time they were referred to us. At sternotomy we did not encounter unexpected vascular anomalies, which has been reported in virtually every other series.

In one instance the length of stenosis was substantial and necessitated end-to-end construction of a patch, a tracheoplasty, so that segments of two rib cartilages were laid end to end. That seemed to work quite well.

We have never encountered a case in which the trachea was so narrow that the piece of rib was too narrow to provide an adequate lumen. I would not say that that is impossible. I am certain that it could happen.

We have not had a problem with healing or air leaks. Most of the children have required an additional stitch or two when the repair was tested for being airtight, but we have not had the problem of torque of cartilage against cartilage, for example, or of sutures tearing through, and we have had no mediastinal soilage or mediastinitis. That probably reflects luck more than any technical skill. 